\title{
Medical trainees warn practice permits will drive away doctors
}

\author{
n Cite as: CMAJ 2019 December 9;191:E1365-6. doi: 10.1503/cmaj.1095835
}

Posted on cmajnews.com on November 21, 2019

$\mathbf{M}$ edical students and resident doctors in Alberta are pushing back against proposals in a new omnibus bill that would restrict where they can practise in the province.

The Alberta Medical Association has already raised concerns that Bill 21 will give the government the power to unilaterally cancel any contract with doctors, without cause. But the controversial bill, now at third reading, is even worse for trainees, say representatives of medical students and resident organizations.

The bill proposes that after April 2022, new doctors in the province will be required to obtain practice permits from the government upon completion of residency training. These permits could restrict new doctors to work only in certain regions and could also limit the type of care they provide, for example, by requiring a specific ratio of community care to hospital services.

"The language is vague and that's giving a lot of residents anxiety," says Dr. Franco Rizzuti, president of the Professional Association of Resident Physicians of Alberta (PARA).

Medical trainees worry that they could complete a residency in a city and then be forced to work several hours away in a remote location, despite lacking experience in rural environments.

"People are jumping to worst-case scenarios and it makes sense because this bill happened really quickly and we haven't been consulted on it," says Taylor Heinzlmeir, president of the Medical Students' Association at the University of Alberta.

Alberta Health Minister Tyler Shandro says the proposed changes are necessary to address the reality that too few physicians in the province are willing to practise in rural areas. "We have more physicians per capita than the national average, yet we have longstanding gaps in access in many parts of the province," he says.

However, medical trainees argue that forcing new doctors to work in rural areas won't fix the problem. "People who have very legitimate reasons for being tied to a larger centre don't end up fulfilling the much-needed work in rural areas," says Alex Corrigan, president of the Calgary Medical Students Association. For example, many doctors have spouses who are able to work only in urban areas. Rather than accept a rural position, they'll move to another province, Corrigan says.

New Brunswick restricted physician billing numbers geographically for decades but abandoned the scheme this year because it was impeding recruitment. Similarly, Nova Scotia recently expanded its tuition relief and bursary programs for rural doctors to all new family doctors, regardless of where they practise in the province, in a bid to attract and retain more physicians.

According to Steve Buick, a spokesperson for Alberta's Minister of Health, the

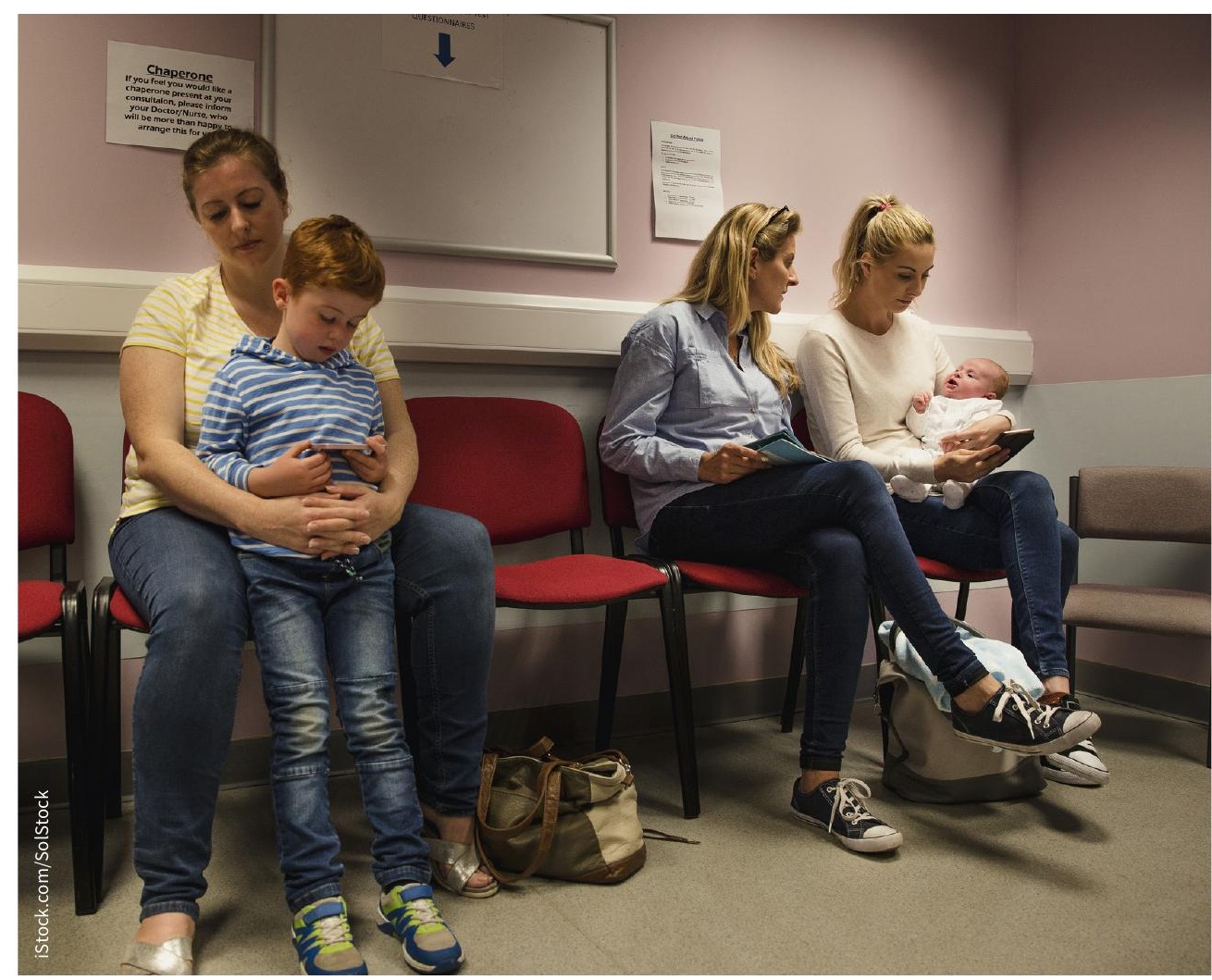

A proposal to control where doctors work won't improve access for rural Albertans, argue medical students and resident physicians. 
situation in Alberta is different because the province has a "strong supply of physicians," while New Brunswick is "struggling with recruitment challenges." $\mathrm{He}$ notes that other provinces act to influence the distribution of doctors; for example, Quebec and Prince Edward Island pay rural doctors at higher rates.

In addition to concerns about a postresidency brain drain, medical students and residents warn that Bill 21 could discourage people from training in Alberta. According to Rizzuti, there is concern about how the bill will affect Canada's residency match. In recent years, record numbers of medical graduates across the country were unable to secure residency positions, in part because unpopular health care reforms in Quebec pushed trainees from that province to seek posi- tions elsewhere. Alberta may suffer a similar exodus.

Family physicians, general internists and pediatricians are more likely to face restrictions under Bill 21, so those specialties could have the most difficulty attracting trainees. "Students who have always wanted to do family medicine could choose another area because they want to be able to stay near family or partners in Calgary," Corrigan explains.

PARA and medical student associations in Alberta are calling on the government to address the shortage of rural doctors in more effective ways. These include developing pipeline programs to ensure more rural Albertans get into medical school and funding more rural clerkships and residencies. "There are a lot of folks who want to do a placement in rural Alberta, or in a regional centre like Red Deer and Lethbridge, but they're being denied that opportunity because there aren't enough preceptors or program funding to have them there," says Rizzuti.

And to entice family doctors to rural areas, Heinzlmeir suggests the government fund team-based "medical homes" in those areas. "If a physician doesn't have access to allied health care, or to some of the same resources that they had when they were training in bigger centres, it can be more difficult to provide good care," he says.

According to Buick, Alberta's government will "continue to support rural recruitment and retention, including programs to expose medical students and residents to rural practice."

Wendy Glauser, Toronto, Ont. 